\title{
ORIGEM DE UAI: UMA HIPÓTESE CAIPIRA
}

\section{ORIGIN OF UAI: A HILLBILLY HYPOTHESIS}

\author{
Hadinei Ribeiro Batista \\ Universidade Federal de Minas Gerais, Belo Horizonte, MG, Brasil
}

\begin{abstract}
Resumo: O principal objetivo deste artigo é testar uma hipótese sugerida por Amaral (1976) sobre a origem da famosa interjeição mineira "uai". Para esse autor, a forma "uai" derivou de um processo de mudança fônica que se iniciou no vocábulo "olhai", no falar de roceiros paulistas.

Palavras-chave: Fonética; Fonologia; mudança fônica.
\end{abstract}

Abstract: The main purpose of this paper is to test a hypothesis suggested by Amaral (1976) about the origin of the famous "uai" mineira interjection. For this author, "uai" form derived from a phonetic change process which began in the word "olhai", in the hillbilly speech from the countryside of the state of São Paulo.

Keywords: Phonetics; Phonology; phonetic change.

\section{Introdução}

A tão famosa expressão do dialeto mineiro - uai - tem sido alvo de investigações acadêmicas nos últimos anos. Embora essa partícula seja considerada um emblema do falar dos mineiros, há polêmicas sobre sua origem.

Albuquerque (2008) registra algumas possibilidades para o surgimento e espraiamento de uai entre os mineiros. Dentre as hipóteses, temos: empréstimo linguístico, brasileirismo e, até mesmo, tratar-se de termo açoriano.

Nosso propósito, neste trabalho, é testar a hipótese de uai ter procedido de um brasileirismo, em que o item lexical olhai, por meio de sucessivas mudanças fonético-fonológicas, teria originado a forma uai. Façamos, inicialmente, um breve histórico dessa hipótese.

\section{Breve histórico - brasileirismo}

Popularmente, é consenso acreditar que a origem de uai se deu em Minas Gerais. De fato, existem evidências de que essa expressão teria se inserido no dialeto mineiro a partir do contato dessa comunidade com imigrantes ingleses e italianos no século XIX. Embora essa hipótese seja fortemente aceita, há outras evidências de que seu surgimento tenha ocorrido no interior de São Paulo, no falar dos roceiros paulistas.

Amaral (1976) registra, no vocabulário do dialeto caipira do interior 
de São Paulo, a interjeição uai e sua variante uiai. Essas expressões eram usadas pelos falantes para indicar surpresa ou espanto. Um fato curioso, que esse autor também assinala, é a existência, nesse mesmo dialeto, das formas oiai, uéi $(\sim$ ué $)$ e uêi $(\sim$ uê) com a mesma acepção de uai. A semelhança sonora entre essas expressões levou o autor a sugerir que a partícula uai é uma forma própria da Língua Portuguesa e que sua origem decorreu de sucessivas mudanças fonético-fonológicas da forma olhai. Nesse sentido, o autor propõe a seguinte escala de alternância/mudança sonora: olhai $\rightarrow$ oiai $\rightarrow$ uiai $\rightarrow$ uai $\rightarrow$ uéi ( $\sim$ ué) $\rightarrow$ uêi $(\sim$ uê).

Embora não tenha sido especificada a função discursiva da forma olhai, todas as outras formas foram registradas pelo autor com função interjetiva. A correlação semântica e sonora entre esses itens fortalece a hipótese de que esse percurso (ou variação) tenha, realmente, ocorrido.

Sem descartar a possibilidade de esses itens constituírem entradas lexicais diferentes na língua, nosso propósito é investigar e explicitar, do ponto de vista fonético e fonológico, a viabilidade de tais mudanças/alternâncias sonoras. Essa tarefa será minuciosamente descrita nas próximas seções. Consideraremos, também, o modelo de difusão lexical para nos ajudar a explicar a implementação dessas mudanças.

\section{Testando a hipótese}

Neste tópico, trataremos, passo a passo, do percurso sonoro olhai $\rightarrow$ uêi. Cada alternância fônica será analisada individualmente e em subtópicos diferentes a fim de que possamos visualizar melhor as mudanças, evitando imprecisões e julgamentos que extrapolem o ponto de vista adotado.

\subsection{Olhai $\rightarrow$ oịai}

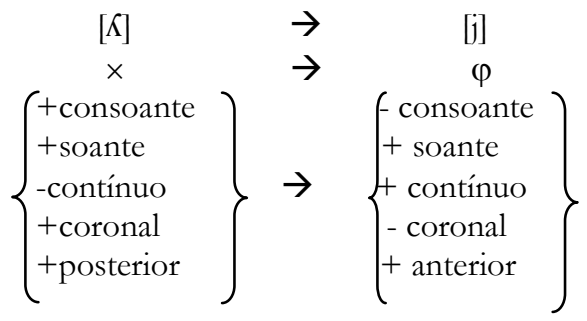

Essa representação nos revela o tipo de alteração que ocorreu no trato vocal para que $/ \varphi /$ fosse emitido em detrimento de $/ \times /$. Observe que houve a perda da constrição e a língua deixou de tocar a região palatal.

O segmento é produzido quando o articulador passivo (parte final do palato duro) é tocado pelo articulador ativo (parte média da língua). A corrente 
de ar é, então, obstruída na linha central do trato vocal, permitindo o escape do ar por ambos os lados de tal obstrução. É, portanto, um som lateral palatal vozeado, pois a corrente de ar produz vibração nas cordas vocais.

Já $/ \times \mid$ é um som aproximadamente palatal, com qualidade semelhante à vogal / $/$. Segundo Cristófaro-Silva (1999), há três alternativas de se articular o dígrafo $\mathbf{l h}$, como em galho. Primeiramente, o falante articula uma consoante lateral palatal, descrito acima, pronunciando [oKaj]. Outra possibilidade de articulação, muito comum no português brasileiro (PB), é produzir uma lateral alveolar (ou dental) com propriedade articulatória secundária de palatalização, ou seja, o falante levanta a ponta da língua em direção aos alvéolos, como se fosse pronunciar a palavra galo. Ao mesmo tempo, o falante eleva a região média da língua em direção ao palato duro, produzindo, portanto, uma consoante lateral alveolar palatalizada, sendo galho, pronunciado como [galjo]. Há, por outro lado, falantes que produzem uma vogal com qualidade de $/ \mathfrak{l}$, ocupando assim, a posição da referida consoante, pronunciando, então, galho, como [gajo].

O que Amaral (1976), portanto, sugere é que a palatal / $\varphi /$, em olhai [oKaj], se modifique para a semivogal em oiai [ojaj]. Vê-se que tal processo é possível de ocorrer no PB, sendo chamado de alofonia da lateral palatal, ou seja, o fonema apresenta três alofones diferentes: $[\varphi]$, [li] e [x]. Uma vez que uma sequência velho [li] pode ser pronunciada [veKo], [veljo] ou [vejo], sem que a troca de alofone modifique o significado da palavra, tem-se, portanto, um caso de alofonia livre. Seguindo esse critério, pode-se, a partir de [oKai] chegarmos a [uai]. Esse processo, inclusive, foi muito comum no dialeto estudado pelo autor. A vocalização de $/ \times / \mathrm{em} / \varphi /$ ocorreu em várias palavras como: espaiado, maio, muié, fiio $=$ espalhado, malho, mulher, filho, etc.

$$
\begin{gathered}
1.2 \underline{\text { Oiai } \rightarrow \text { uniai }} \\
{[\mathrm{o} \varphi \cup \alpha \varphi] \rightarrow[\cup \psi \cup \alpha \varphi]} \\
/ \mathrm{o} / \\
\left\{\begin{array}{l}
+ \text { silábico } \\
- \text { alta } \\
+ \text { recuada } \\
+ \text { arredondada }
\end{array}\right\} \rightarrow\left\{\begin{array}{l}
+ \text { silábico } \\
+ \text { alta } \\
+ \text { recuada } \\
+ \text { arredondada }
\end{array}\right\}
\end{gathered}
$$

Primeiramente, o que se tem em vista é a troca da vogal /o/ para a 
vogal / $/$. Em termos de análise, as vogais são classificadas de acordo com três parâmetros: altura da língua ${ }^{1}$, posição horizontal da língua e arredondamento dos lábios. Nosso esquema mostra que a diferença é tênue e corresponde apenas à altura da língua no trato vocal. Portanto, a mudança em análise envolve sons foneticamente semelhantes (SFS).

A vogal /o/ é articulada com a elevação da língua para uma posição média-alta no trato vocal, com a parte posterior (de trás) da língua e com o arredondamento dos lábios. Por isso, classifica-se tal vogal como média-alta posterior arredondada. Já a vogal $/ \mathrm{v}$ é realizada com a parte posterior da língua em uma posição alta e com um maior grau de arredondamento dos lábios. Classifica-se, então, tal vogal como alta posterior arredondada.

Existe um processo no $\mathrm{PB}$ que diz respeito à troca de $/ \mathrm{o} /$ para $/ \mathrm{v} /$, chamado de alçamento. $\mathrm{O}$ alçamento ocorre quando as vogais médias $/ \varepsilon / \mathrm{e}$ /o/ são pronunciadas, respectivamente, como as altas [1] e [u]. Pode-se notar essa mudança em várias regiões do Brasil, em palavras como $[\mu \iota \cup v ı v \mathrm{Y}]$ e $[\beta \cup \cup v i \tau \mathrm{Y}]$. Note-se, contudo, que tal mudança ocorre quando as vogais / $/$ / e /o/ estão em posição pretônica, ou seja, na sílaba que antecede a tônica, como visto nos exemplos acima. Por isso chama-se tal fenômeno de alçamento das vogais pretônicas. $O$ alçamento de $/ \varepsilon /$ para $/ \mathrm{l} /$ e de $/ o /$ para $/ \mathrm{U} /$ é possível por elas serem SFS (sons foneticamente semelhantes), ou seja, as vogais $/ \varepsilon, 1 / \mathrm{e}$ as /o,v/ distinguem-se por apenas uma propriedade articulatória (CRISTÓFARO-SILVA, 1999), a saber: a altura da língua no trato vocal. Essa é uma das razões pelas quais a vogal $/ \varepsilon /$ não poderia alçar para $/ \mathrm{v}$, já que elas se distinguem por mais de uma propriedade articulatória (altura, recuo e arredondamento).

Potencialmente, todas as vogais médias pretônicas $-/ \varepsilon, \mathrm{O} /-$ podem sofrer o processo de alçamento, porém varia de dialeto para dialeto.

No caso do dialeto estudado por Amaral (1976), o alçamento de /o/ para / $/$ foi muito comum em palavras como: cuzinha, dumingo e, sobretudo, na forma infinitiva de verbos terminados em -ir: bulí(r), tussí( $(\mathrm{r})$, etc. Porém, o autor registra que formas derivadas e flexionadas - quando o /o/ é tônico nas palavras primitivas - o alçamento não acontece: locura, boquêra, porcada, etc. Se considerarmos olhai como derivado de olho, a mudança em análise não seria prevista nesse dialeto. Além disso, na forma infinitiva de verbos terminados em -ar, a tendência é evitar o alçamento. Observe que o verbo olhar, no PB atual, conserva o /o/ $\square /$ em todas as suas conjugações.

Embora a escala de mudança proposta pelo autor sugira que o

1 A altura das vogais pode variar em quatro valores: alta, média-alta, média-baixa, baixa (LADEFOGED, 1984). 
processo se deu de forma linear, a vocalização de $/ \times /$ não autoriza $o$ alçamento de /o/ para / $/$ como explicado anteriormente. Sendo assim, o fenômeno não seria produtivo na gramática do dialeto em estudo, nem quiçá do próprio $\mathrm{PB}$. De qualquer forma, as observações aqui elencadas não garantem tal restrição. Não são comuns, no PB, palavras com sequências semelhantes a de oiai, que nos permitam tirar conclusões mais seguras. Por outro lado, se compararmos a forma "oiai" com palavras como goiaba e boiaçu, o alçamento é possível, dado que pronúncias como guiaba e buiuçu são comuns em alguns dialetos caipiras.

Apesar dos impedimentos relacionados com a forma verbal e com os processos de derivação, dispomos de argumentos consistentes que nos permitam afirmar que o alçamento é possível na forma em análise. Veja que /o/, em oiai, é uma vogal pretônica e que seu valor semântico difere do uso de sua forma como verbo ou como substantivo do qual derivaria. Aliás, como emprego de interjeição (tão recorrente na fala espontânea), o alçamento se torna ainda mais previsível. Como o alçamento de pretônicas constitui um fenômeno geral no $\mathrm{PB}$, as restrições aqui elencadas não são suficientes para justificar a inviabilidade da mudança.

$$
\begin{aligned}
& 1.3 \quad \text { Uiai } \rightarrow \text { uai } \\
& {[\cup \varphi \cup \alpha \varphi] \rightarrow[\cup \cup \alpha \varphi]} \\
& \psi \rightarrow \varnothing /{ }_{\psi} \\
& \psi \rightarrow \varnothing / u^{-}
\end{aligned}
$$

A fim de discutirmos o apagamento do glide ${ }^{2}[\varphi]$ no ditongo [U $\left.\varphi\right]$ em $[\cup \varphi \cup \alpha \varphi]$, precisamos, em um primeiro momento, conceituar ditongo, glide e o que vem a ser esse processo de apagamento e como ocorre.

Primeiramente, glide é também conhecida como semivogal, ou seja, é a vogal sem proeminência acentual nos ditongos (CRISTÓFARO-SILVA, 1999).

Cagliari (2007), ao discutir sobre ditongos, vê uma dificuldade em conceituação por parte de vários autores. Bloomfield (1933) diz que um ditongo é uma vogal precedida por $[\varphi]$ ou $[\mathrm{Y}]$. Abercrombie (1967), por sua vez, afirma que ditongo é uma vogal que muda de qualidade constantemente.

Cagliari (2007), aperfeiçoando os conceitos dos referidos autores, coloca o ditongo como sendo duas vogais que ocorrem na mesma sílaba. Uma

\footnotetext{
${ }^{2}$ Glide é o termo usado em inglês para um dos dois sons que compõe um ditongo. Como não são nem consoantes nem vogais, normalmente recebem essa denominação também em português. Neste artigo, optamos por utilizar o termo em inglês.
} 
diferença entre um ditongo e uma sequência de duas vogais reside no fato de:

a) No ditongo, a língua segue um movimento contínuo de uma vogal à outra, produzindo uma qualidade vocálica em constante mudança;

b) O ditongo apresenta uma duração menor do que uma sequência de duas vogais;

c) Os ditongos ocorrem na mesma sílaba.

Além disso, os ditongos são subdivididos em duas classes: crescentes ou decrescentes. Os ditongos crescentes, segundo Cristófaro-Silva (1999), são aqueles em que a proeminência acentual ocorre na primeira vogal, como em $[\mathrm{Z} \cup \mathrm{I}: \zeta \alpha \delta \mathrm{Y}]$, e ditongos decrescentes, sendo aqueles em que a proeminência acentual ocorre na segunda vogal, como em $[\mathrm{ZY} \text { : } \zeta \alpha \delta \mathrm{Y}]^{3}$.

De acordo com Bisol (1989 p. 89), "no português, há duas classes de ditongo: ditongo pesado e ditongo leve". Ela considera os primeiros como ditongos verdadeiros e os segundos, como falsos. Os ditongos leves ou falsos são aqueles que tendem a sofrer monotongação ${ }^{4}$, ou seja, deixam de ser ditongo para ser monotongo, como em $\mathrm{p}[\varepsilon \varphi] \mathrm{xe} \sim \mathrm{p}[\varepsilon] \mathrm{xe}$. Já o ditongo pesado ou verdadeiro não sofre tal processo, como em $\mathrm{p}[\alpha \mathrm{Y}]$ ta $\sim *_{\mathrm{p}}[\alpha]$ ta. Observe que, nesse caso, a restrição pode decorrer do fato de a monotongação implicar variação semântica.

Esses monotongos surgem por causa da proximidade da consoante palatal. Segundo a autora, o surgimento acontece porque essas consoantes têm o que se chama articulação secundária: uma consoante que possui tanto traços consonantais propriamente ditos quanto traços vocálicos. O traço vocálico da palatal então se espraia em contextos específicos: precedido de $/ \varepsilon /$ ou $/ \alpha /$, como em band $[\varepsilon]$ ja e $c[\alpha] \times$ xa (PEREIRA, 2004). A saber, uma restrição quanto à monotongação é que a ditongação se mantém em sílaba única ou final tônica: mandei, lei, falei, vai, mau. Portanto, pode-se dizer que, no português falado no Brasil, a forma mantida na escrita é a ditongada, mas, em seu uso oral, convive-se com o apagamento das semivogais $/ \varphi /$ e $/ \omega /$.

Com base nos conceitos apresentados sobre ditongos, podemos afirmar que o segmento $[\cup \varphi]$ em $[\cup \varphi \cup \alpha \varphi]$ é: ditongo decrescente pesado.

Ainda sobre os ditongos, Bisol (1989) pontua que a monotongação do ditongo $/ \varepsilon \varphi /$ antes da vogal $/ \alpha /$, como em meia, teia, cheia, parece não ser mencionada na literatura. Portanto, não é comum no $\mathrm{PB}$ o apagamento do glide $/ \mathrm{j} /$ diante de /a/ em fronteira de sílaba.

Contrariamente, o mesmo não se pode afirmar sobre o dialeto caipira estudado por Amaral (1976). Segundo o autor, é comum, nesse dialeto, a

\footnotetext{
${ }^{3}$ No português brasileiro, os símbolos $[\mathrm{I}]$ e $[\mathrm{Y}]$ são também usados para indicar os glides $[\varphi]$ e $[\mathrm{Y}]$ nos ditongos respectivamente (CRISTÓFARO-SILVA, 1999).

${ }^{4} \mathrm{Um}$ estudo sobre a monotongação dos ditongos orais decrescentes em várias regiões do Brasil pode ser visto em Cabreira (1996; 2000).
} 
alternância entre $/ \varepsilon \varphi /$ e $/ \varepsilon /$ diante de $/ a /$. Sendo assim, palavras como ceia e veia são também pronunciadas como cêa e vêa. Dessa forma, ao contrário do que afirma Bisol(1989), a síncope de / $\mathrm{j} /$ diante da vogal /a/ é prevista nesse dialeto e, por isso, sua dificuldade de ocorrer não constitui um fenômeno geral do PB. Um caso curioso é o da palatalização de $/ \cup \phi 1 \times \alpha /$, cuja pronúncia passou a ser fiia, ou seja, não se registrou a síncope do / l/. Dessa forma, não podemos afirmar que essa síncope faça parte da gramática desse dialeto.

Sendo assim, nada se pode afirmar se o processo de monotongação ocorreria no ditongo $/ U \varphi /$ seguido da vogal / $\alpha /$, como em uiai. Dados como cuia, buia, cuiara, cuiarana e luia comprovam que o apagamento do glide $/ \varphi /$ não é produtivo. Um fenômeno similar, que pode reforçar ainda mais essa conclusão, é a pronúncia de palavras terminadas em -ulho(a). Observe que podemos ter, respectivamente, em alguns dialetos, as pronúncias [o $\mid \cup \gamma \cup \varphi]$ e $[\alpha \cup \gamma \cup \varphi \leftrightarrow]$ para as formas orgulho e agulha e assim por diante, sem o apagamento de $[\varphi]$. Portanto, pode-se concluir que o ditongo / $\varphi / \mathrm{em}$ $[\cup \varphi \cup \alpha \varphi]$ é considerado verdadeiro, não podendo sofrer o processo de monotongação, tornando-se $[\cup \cup \alpha \mathrm{I}]$.

Analisamos, então, a transformação de uiai para uai sob a perspectiva de Bybee (1991, p. 01). Essa autora, na Fonologia de Uso, diz que o uso da língua acarreta em mudança da forma e do conteúdo do sistema sonoro: "a frequência com a qual palavras isoladas ou sequências são usadas e também a frequência com a qual certos padrões recorrem na língua, afeta a representação mental e, em alguns casos, até a forma fonética das palavras". Pode-se tentar imaginar um uso muito grande de [ $\cup \varphi \cup \alpha \varphi]$ que, em algum dado momento da história desse dialeto, alguns falantes passaram a pronunciar $[\cup \cup \alpha \varphi]$, havendo, portanto, o apagamento do glide $[\varphi]$.

A frequência de uso e o domínio semântico são determinantes para o grau de exposição de um item à mudança de som (KRISHNAMURTI, 1978). Como o uso interjetivo é tão recorrente na conversação espontânea, a manifestação contínua de [ $\varphi \varphi \cup \alpha \varphi$ ] pode ter acarretado a pronúncia $[\cup \cup \alpha \varphi]$.

Por fim, não obstante tenha havido exemplos de queda de $/ \varphi /$ diante da vogal $/ \alpha /$ como em vêa e cêa, a síncope de $/ \varphi /$ depois de $/ v /$ não é prevista nesse dialeto. Desse modo, podemos afirmar que a alternância entre $[\cup \varphi \cup \alpha \varphi]$ e $[\cup \cup \alpha \varphi]$ trata-se de uma modificação isolada ou acidental. Nesse dialeto, uma forma não pode, naturalmente, dar origem à outra.

Retomando as regras propostas no início desta seção, podemos concluir que o $/ \varphi /$ sofre queda diante de $/ \alpha /$ desde que precedido de $/ \varepsilon /$. Porém, há restrições quanto ao cancelamento de $/ \varphi /$ depois de $/ \nu /$. Sendo

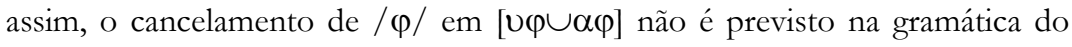
dialeto em estudo. 


\section{4 uại $\rightarrow$ ué(i) $\sim$ uê(i) \\ ai $\rightarrow$ é(i) $\sim \hat{e}(i) / \ldots$}

Nesta subseção, não faremos uma descrição detalhada da alternância referida acima pelo fato de nosso propósito principal ser a testagem da possibilidade de $[\cup \cup \alpha \varphi]$ ter originado de $[o: \times \alpha \varphi]$.

Sobre a viabilidade fonético-fonológica do grupo vocálico ai se tornar $/ \mathrm{E} /$ ou $/ \varepsilon /$, podemos elencar exemplos do próprio dialeto caipira em estudo. Amaral (1976) afirma que, antes da palatal [ $\Sigma]$, é muito comum a queda de $[\varphi]$ no grupo $[\alpha \varphi]$, como ocorre em: baxo, baxêro, faxa, caxa, paxão. Além disso, a alternância de $[\alpha \varphi]$ em $[E \varphi]$ foi atestada em palavras como téipa e réiva. Desse modo, são previstas, empiricamente, na gramática desse dialeto, tais alternâncias.

\section{Modelos: Difusão Lexical e Neogramático}

Os neogramáticos acreditam que a mudança sonora é linear e condicionada por fatores estritamente fonéticos. Essa visão desconsidera qualquer tipo de mudança abrupta. Por outro lado, há autores que afirmam que as palavras mudam suas pronúncias de maneira foneticamente abrupta e lexicalmente gradual (WANG; CHEN, 1977). Embora essas afirmações pareçam conflitantes, Labov (1981) tenta acomodar os dois modelos em seu estudo sobre a mudança fônica no inglês falado na Filadélfia.

Oliveira (1991) contraria o trabalho de Labov (1981) e, ao analisar o trabalho de Viegas (1987) sobre a controvérsia - Processo Neogramático ou Difusão Lexical -, mostra que a mudança sonora não pode ser explicada apenas do ponto de vista estritamente fonético. Viegas (1987) analisa palavras que, embora pareçam seguir uma regra de alternância fônica, contraexemplos foram atestados, ou seja, a regularidade é aparente. Por exemplo, alçamento de $/ \varepsilon / \mathrm{em} / \mathrm{l} /$ é um fenômeno comum no PB, como por exemplo: perigo, feliz e menino. Porém, em contexto idêntico, há contraexemplos: perito, felino e meninge. Estes últimos não são pronunciados pelos falantes com [1]. Poderíamos imaginar que a frequência de uso desses itens lexicais poderia interferir na possibilidade de mudança fônica. Se fosse esse o caso, como explicar o uso de palavras como cebola e cenoura em contraste com ceroula? Esta última, embora de uso menos frequente, permite o alçamento de $/ \varepsilon / \mathrm{em}$ $/ \mathfrak{l}$ enquanto as primeiras não.

Casos, como os que expomos acima, levaram Oliveira (1991) a estabelecer uma posição radical. O autor afirma que as mudanças sonoras são todas lexicalmente implementadas. Para ele, o resultado final de uma mudança 
pode levar à crença de que o processo ocorreu de forma regular, mas isso não prova se a mudança foi ou não lexicalmente colocada em prática.

Além disso, esse autor explica que a alternância $\mathrm{X} \rightarrow \mathrm{Y} / \mathrm{Z}$, atestada como essencialmente fonética, constitui uma exceção, como é o caso, em alguns dialetos do $\mathrm{PB}$, a realização de $/ \tau / \mathrm{em} / \tau \Sigma /$ diante de $/ \mathfrak{l} /$. Outro caso é a já citada redução de $/ \varepsilon \varphi / \mathrm{em} / \varepsilon /$ diante de $/ \Sigma /$. Mesmo assim, diante de nasais, os casos não são claros, pois podemos ter alternância em queima $[\cup \theta \varepsilon)(\varphi) \mu \leftrightarrow]$ e pimenta do reino $[\mid \varepsilon)(\varphi) v v]$, mas não na palavra reino isolada $[\varepsilon) \varphi v u]$.

Isso mostra que o modelo neogramático não é suficiente para explicar as mudanças sonoras que ocorrem nas línguas. O modelo de difusão lexical, apesar de parecer complementar, assinala que a regularidade é aparente e que nem todos os casos se submeterão às regras descritas.

Precisamos levar em conta, em nosso trabalho, essas leituras para que possamos tirar conclusões mais acertadas sobre a escala de alternância sonora. Embora nossa análise tenha sido, de certo modo, estritamente fonética e linear, o modelo de difusão lexical também deve ser considerado, já que nos autoriza afirmar que a referida escala de Amaral (1976) não se trata apenas de uma idealização.

\section{Conclusões}

Nosso objetivo principal neste artigo foi demonstrar se a hipótese da escala de alternância sonora - olhai $\rightarrow$ oiai $\rightarrow$ uiai $\rightarrow$ uai $\rightarrow$ uéi $(\sim$ ué $) \rightarrow$ uêi $(\sim$ uê) - proposta por Amaral (1976), é viável dentro do quadro teórico da Fonética e da Fonologia. Embora essa escala se alongue a dois níveis além da expressão uai, nosso enfoque se deu nessa expressão, haja vista nosso interesse em investigar e desvendar sua verdadeira origem.

De acordo com as análises apresentadas em cada seção, podemos concluir que:

1. A trajetória Olhai $\rightarrow$ oiai é prevista dentro do quadro teórico em estudo, uma vez que a palatalização e vocalização de $/ \times /$ é um fenômeno bastante comum no $\mathrm{PB}$ e na gramática do dialeto em estudo. Tanto que diversas outras palavras, nesse mesmo dialeto, sofreram o mesmo processo;

2. A alternância Oiai $\rightarrow$ uiai, apesar de polêmica, mostrou-se passível de ocorrer. Os impedimentos relacionados com a forma verbal e com o processo de derivação não permitem afirmações seguras. Dessa forma, prevaleceu o fenômeno presente na gramática do PB e do dialeto em estudo o alçamento da pretônica /o/. Como visto, não foi econômico o número de palavras que passou pela mesma alternância. Outro fator que, naturalmente, possa ter facilitado o alçamento é o uso expressivo de oiai na conversação 
espontânea.

3. A alternância Uiai $\rightarrow$ uai representou a análise mais complexa. Embora o dialeto estudado por Amaral (1976) permita a queda de / $\varphi /$ diante de $/ \alpha /$, há impedimentos relacionados com a queda desse segmento depois de / /. Não há registros dessa natureza nos dados coletados pelo autor. No PB, os exemplos elencados - cuia, buia, cuiarana, cuiara e luia e as palavras com terminação em -ulho(a) - apontam para uma possível restrição. Essa informação nos forçou a assumir que essa alternância constitui um fenômeno acidental, ou seja, ela não está prevista na gramática do PB e, possivelmente, seja, de fato, um processo geral que abarque esse dialeto caipira.

Contudo, não podemos afirmar, categoricamente, que a escala proposta por Amaral (1976) se trate de um equívoco.

As mudanças fônicas são previstas na gramática do PB e, em alguns casos, na gramática específica do dialeto caipira. Embora não tenhamos atestado o cancelamento do glide $/ \varphi /$ depois de $/ \mathrm{v} /$, isso não nos autoriza

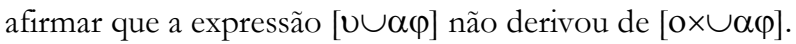

A análise de Viegas (1987) nos mostrou que as mudanças não são de todo sistemáticas, ou seja, em alguns itens atestamos alternâncias e em outros, em contexto fônico idêntico, não. No caso do dialeto em análise, todas as formas presentes na escala foram registradas na fala dos caipiras. Isso quer dizer que o uso de uma forma não substituiu a outra. Essas formas coexistem com a mesma função semântica - interjeição - e seus usos variam socialmente e/ou individualmente.

A escala aqui investigada, embora linear, sugere apenas que uma forma derivou da outra de maneira divergente, ou seja, a implementação de [u $\cup \alpha \varphi]$ pode ter ocorrido de maneira abrupta, sem necessariamente depender das alternâncias que a antecedem.

Por fim, levando em consideração os estudos elencados neste artigo, principalmente o modelo sobre a difusão lexical, podemos afirmar que a hipótese da origem de $[\cup \cup \alpha \varphi]$ em $[o \times \cup \alpha \varphi]$ é potencialmente prevista no dialeto caipira aqui discutido.

Além disso, como sugestão para estudos futuros, salientamos que a forma olhai é arcaica e de uso culto. Sendo assim, seria interessante uma pesquisa que pudesse investigar mais cuidadosamente o uso dessa expressão nessa comunidade, a fim de esclarecer seu uso como interjeição. Esse estudo poderia nos levar a outros níveis de análise e possibilitaria um levantamento historicamente mais preciso sobre a origem da mais famosa expressão mineira - uai. 


\section{REFERÊNCIAS}

ABERCROMBIE, D. Studies in Phonetics and Linguistics. London: Oxford University Press, 1967, p. 16-44.

ALBUQUERQUE, I. Hipóteses sobre a origem de uma interjeição. In: RAMOS , J.; COELHO, S. (Orgs). Português brasileiro dialetal: temas gramaticais. Campinas, SP: Mercado de Letras, 2013.

AMARAL, A. O dialeto caipira. São Paulo: HUCITEC, 1976.

BISOL, L. O ditongo na perspectiva da fonologia atual. In: D.E.L.TA. v.5, n. 2, p. 185-224, 1989.

BLOOMFIELD, L. Language. Holt, Rinehart and Winton. New York, 1993 BYBEE, J. Phonology and language use. Cambridge: Cambridge University Press, 2001.

CABREIRA, S. H. A monotongação dos ditongos orais decrescentes em Curitiba. Dissertação (Mestrado em Letras). Pontifícia Universidade Católica do Rio Grande do Sul. Porto Alegre - RS, 1996.

CAGLIARI, L. C. Elementos de Fonética do Português Brasileiro. São Paulo: Paulistana, 2007. 194 p.

CRISTÓFARO-SILVA, T. Fonética e Fonologia do português. 2. ed. São Paulo: Contexto, 1999.

LABOV, W. The study of language in this social context. In: Sociolinguistic Patterns. Philadelphia: University of Pennsylvania Press, 1972.

LABOV, W. Resolving the neogrammarian controversy. In: Language. Washington, v.57, n.2, 1981.

ODDEN, D. Introducing Phonology. Cambridge: Cambridge University Press, 2005.

OLIVEIRA, M. A. The neogrammarian controversy revisited. International Journal of the sociology of language. Berlin, v. 89, 1991.

PEREIRA, G. Monotongação dos ditongos /aj/, /ej/, /ow/ no português falado em Tubarão (SC): estudo de casos. Dissertação (Mestrado em Ciências da Linguagem). Universidade do Sul de Santa Catarina, Tubarão SC, 2004.

TOLEDO, E. E. \& MONARETTO, V. N. de O. A redução de ditongos orais decrescentes no português brasileiro do sul do Brasil: descrição e generalização, 2010.

VIEGAS, M. do C. Alçamento das vogais médias pretônicas: uma abordagem sociolinguística. 231 p. Dissertação (Mestrado em Letras). Universidade Federal de Minas Gerais. Belo Horizonte - MG, 1987. 